\title{
ERRATUM
}

\section{Advanced neuroimaging in traumatic brain injury: an overview}

TO THE READERSHIP: An error appeared in the article by Smith et al. (Smith LGF, Milliron E, Ho M-L, et al. Advanced neuroimaging in traumatic brain injury: an overview. Neurosurg Focus. 2019;47[6]:E17).

A reference cited in the introduction was incorrect. The research was attributed to Moen et al., 2014; the correct reference is Moenninghoff et al., 2015. The new reference has been added to the list and the sentence appears below with the correct attribution.

Work done by Moenninghoff et al. has demonstrated that UHF SWI MRI reveals an average of $41 \%$ more traumatic microbleeds caused by DAI than does 3T SWI, and these lesions appear larger on UHF SWI MRI. ${ }^{83}$ 2021.

The article has been corrected online as of January 1,

Luke G. F. Smith, MD

The Ohio State University Wexner Medical Center, Columbus, $\mathrm{OH}$

INCLUDE WHEN CITING

DOI: 10.3171/2020.11.FOCUS19652a.

CAANS 2021, except where prohibited by US copyright law 